\title{
Solar cell fabricated on welded thin flexible silicon
}

Maik Thomas Hessmann ${ }^{1, a}$, Thomas Kunz ${ }^{1}$, Taimoor Ahmad ${ }^{1}$, Da Li ${ }^{1}$, Stephan Wittmann ${ }^{1}$, Arne Riecke ${ }^{1}$, Jan Ebser $^{2}$, Barbara Terheiden ${ }^{2}$, Kristian Cvecek ${ }^{3}$, Michael Schmidt ${ }^{1}$, Richard Auer ${ }^{1}$, and Chistoph J. Brabec ${ }^{1,4}$

1 Bavarian Center for Applied Energy Research (ZAE Bayern), Haberstr. 2a, 91058 Erlangen, Germany

2 Department of Physics, University of Konstanz, Universitätsstr 10, Box 676, 78464 Konstanz, Germany

3 BLZ-Bavarian Laser Center, Konrad-Zuse-Str. 2-6, 91052 Erlangen, Germany

4 i-MEET: institute Materials for Electronics and Energy Technology, University of Erlangen-Nuremberg, Martensstr. 7, 91058 Erlangen, Germany

Received: 5 August 2015 / Received in final form: 30 October 2015/ Accepted: 6 November 2015

Published online: 11 December 2015

(C) Hessmann et al., published by EDP Sciences, 2015

\begin{abstract}
We present a thin-film crystalline silicon solar cell with an AM1.5 efficiency of $11.5 \%$ fabricated on welded $50 \mu \mathrm{m}$ thin silicon foils. The aperture area of the cell is $1.00 \mathrm{~cm}^{2}$. The cell has an open-circuit voltage of $570 \mathrm{mV}$, a short-circuit current density of $29.9 \mathrm{~mA} \mathrm{~cm}^{-2}$ and a fill factor of $67.6 \%$. These are the first results ever presented for solar cells on welded silicon foils. The foils were welded together in order to create the first thin flexible monocrystalline band substrate. A flexible band substrate offers the possibility to overcome the area restriction of ingot-based monocrystalline silicon wafers and the feasibility of a roll-to-roll manufacturing. In combination with an epitaxial and layer transfer process a decrease in production costs can be achieved.
\end{abstract}

\section{Introduction}

Silicon solar cells are following the recipe of improving efficiency and reducing material usage to consolidate their position on the market. Thus silicon thin-film solar cells are in the focus of interest due to the low silicon usage as well as the potential lower production costs. In 2012, the porous silicon (PSI) layer transfer process has proved that high efficiency values can be obtained. Efficiency values of up to $19.1 \%$ (aperture area: $3.98 \mathrm{~cm}^{2}$ ) have been reached at a thickness of $43 \mu \mathrm{m}$ by Brendel and co-workers [1,2]. This result was even excelled by the company Solexel, who reported also a $43 \mu \mathrm{m}$ thick solar cell but with an area of $156 \mathrm{~mm} \times 156 \mathrm{~mm}$ based on a PSI layer transfer process with a world record efficiency of $20.1 \%$ (aperture area: $242.60 \mathrm{~cm}^{2}$ ) [3-5]. Reuse cycles of above 50 are already achieved without any degradation effects [4].

ZAE Bayern developed a method of producing a largearea substrate for solar cell production called "extendedmonocrystalline-silicon-base-foil" (EMOSiB). This substrate offers the possibility of high efficiency solar cells while reducing the material usage at the same time. An illustration of the EMOSiB is depicted in Figure 1. This band substrate would be the first monocrystalline silicon band substrate, further details are published elsewhere [6-8]. In short, an endless thin and flexible band

\footnotetext{
a e-mail: maik.hessmann@zae-bayern.de
}

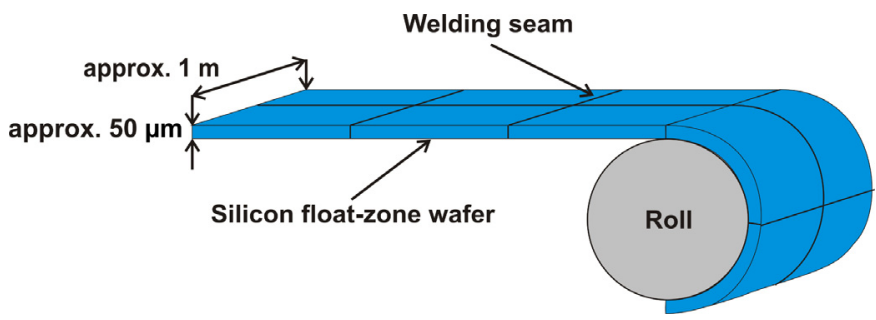

Fig. 1. Illustration of the EMOSiB, which consists of several individual silicon foils. The foils are welded together to the first monocrystalline band substrate. For further details for the solar cell manufacturing process see [8].

substrate of silicon is suggested as an epitaxial seed layer for the roll-to-roll production of crystalline solar cells. The lateral bonding of several thin single wafers to a band substrate are established by a laser welding process, for further details see $[9,10]$. Other approaches for lateral bonding are rare, only one other concept exists, and is published by Werner et al. [11]. Within this concept the gap between two silicon wafers are closed by lateral epitaxy. No results have been published since it was introduced in 2001.

The EMOSiB itself has to be manufactured by thin silicon wafers grown as ingots. A low thickness of the joined foils is essential for sufficient flexibility of the resulting substrate. By using an epitaxial process combined with 


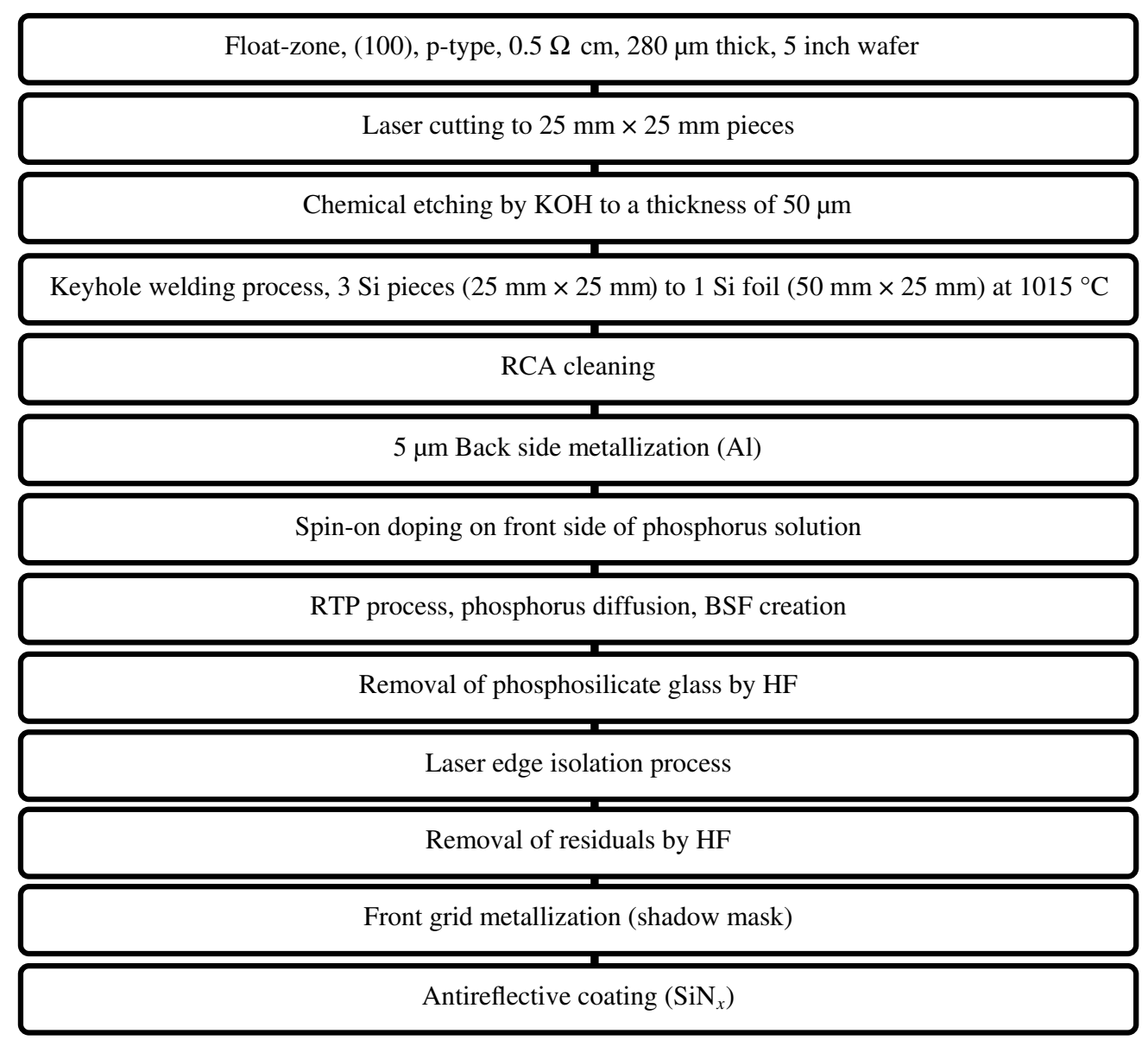

Fig. 2. Process flow diagram for solar cells on top of keyhole welded silicon foils as prepared in this work.

a layer transfer process such as PSI all necessary silicon layers for solar cell production can be produced from the gas phase afterwards $[1,12]$ and the initial silicon foil can be reused several times like in the PSI process [4]. Additionally, the EMOSiB offers the opportunity of an industrial roll-to-roll process for crystalline silicon solar cell fabrication.

This work shows the first solar cells manufactured on keyhole welded silicon thin foils. The flexible foils are obtained by chemical thinning of standard wafers. As the focus of this paper is on cell processing on thin laser-welded foils, no layer transfer or epitaxy is used so far. We discuss and analyze results from the AM1.5 measurement as well as quantum efficiency measurements. Cells at different areas of the welded sample are compared in order to study the influence of the area directly hit by the laser during welding.

\section{Material and methods}

\subsection{Device fabrication}

The process flow of the solar cell production is depicted in Figure 2 and started with $280 \mu \mathrm{m}$ thick, 5 inch in diameter float-zone grown silicon wafers with an orientation of (100), $p$-type, boron doped with a resistivity of 0.45 $0.55 \Omega \mathrm{cm}$. The wafers were laser cut into $25 \mathrm{~mm} \times 25 \mathrm{~mm}$ pieces using a Nd: $\mathrm{YVO}_{4}$ laser (Rofin-Sinar Laser $\mathrm{GmbH}$, model: Power Line E20). The thickness of the pieces was decreased by etching in potassium hydroxide $(\mathrm{KOH})$ solution to approx. $50 \mu \mathrm{m}$ followed by a RCA cleaning using a system of Kufner Nassprozesstechnik GmbH. The $\mathrm{KOH}$ concentration was $22 \%$ and the solution was kept constantly at $85^{\circ} \mathrm{C}$.

Before the welding process began the silicon foils were placed on a specimen holder of fused quartz glass in a crucible furnace and the temperature was increased to $1015^{\circ} \mathrm{C}$ in a nitrogen atmosphere. The laser beam was introduced through a fused quartz window in the furnace, for further details see [1]. The three silicon foils were keyhole welded to one silicon foil, two were placed in butt joint geometry and one in the middle at the back side of the other two as depicted in Figures 3 and 4. Further information about Keyhole welding are published elsewhere $[9,10]$. For welding a ytterbium single mode fiber laser model YLR-1000-SM made by the company IPG Photonics was used. This is a continuous wave laser with a wavelength of $1075 \mathrm{~nm}$, a very high beam quality $\left(M^{2}<1.1\right)$ and a maximum power of approx. $1000 \mathrm{~W}$. Additionally a galvanometer scanner system with an objective focal length of $370 \mathrm{~mm}$ was used to focus and deflect the laser beam 


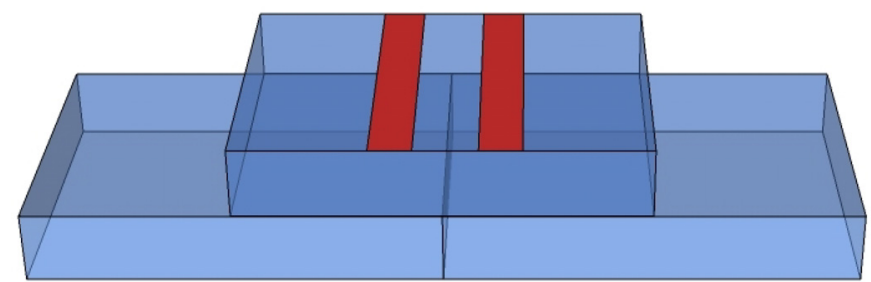

Fig. 3. Illustration of the keyhole welding geometry. Two silicon foils were placed in butt joint geometry and one in the middle at the back side of the other two. The area influenced by welding is colored red. Within the red colored area several keyhole welding lines were applied as depicted in Figure 4a.

a)

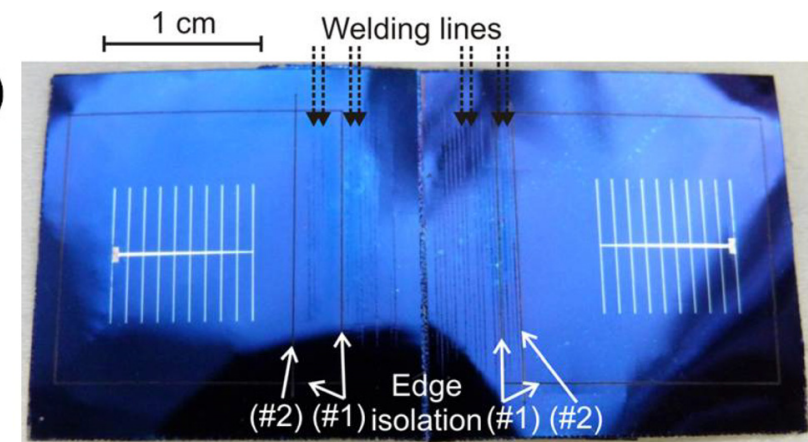

b)

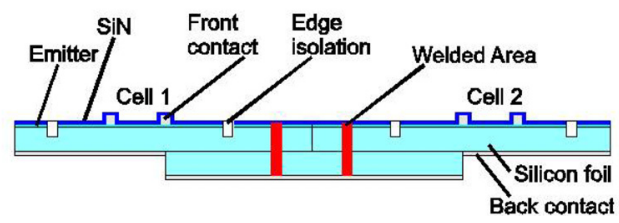

Fig. 4. (a) Photograph of two solar cells fabricated in the silicon foil. Two Si pieces $(25 \mathrm{~mm} \times 25 \mathrm{~mm})$ can be seen at the front and one $(25 \mathrm{~mm} \times 25 \mathrm{~mm})$ piece is underneath. Investigated cell areas were either with (edge isolation line \#1) or without (additional isolation line \#2) locations hit by the welding laser. (b) Schematic cross section of this solar cell design.

onto the sample surface. The resulting laser beam on the silicon foil surface had a spot diameter of $80 \mu \mathrm{m}$. Two times twenty lines with several keyhole welding spots were applied to increase the probability of welding through both silicon foils. Afterwards a RCA cleaning step was applied.

On the back side $5 \mu \mathrm{m}$ aluminum was deposited by an electron beam evaporation system of Pfeiffer Vacuum (model: Classic 570). The phosphorus emitter was created by spin-on doping using the model Spin 150 from APT GmbH. Afterwards the welded foils were annealed in a nitrogen/oxygen atmosphere at $85^{\circ} \mathrm{C}$ for $10 \mathrm{~s}$ in a rapid thermal processing (RTP) furnace (UniTemp GmbH model: UTP 1100). Also a back surface field (BSF) was established, for further information see $[13,14]$. Followed by the removal of the phosphosilicate glass by a $2 \%$ hydrofluoric acid ( $\mathrm{HF}$ ) etch step. For the electronic isolation, a laser edge isolation process (Rofin-Sinar Laser GmbH, model: Power Line E20) was applied. Created residuals were removed by $2 \% \mathrm{HF}$. Afterwards, the front contact grid, with
Ti $30 \mathrm{~nm} / \mathrm{Pd} 30 \mathrm{~nm} / \mathrm{Ag} 5 \mu \mathrm{m}$ layers were formed by using shadow masks in an electron beam evaporator using a Pfeiffer Vacuum system model: Classic 570. A silicon nitride layer was deposited by plasma-enhanced chemical vapor deposition (PECVD) on the front side as antireflective coating (Roth \& Rau GmbH, model: AK1000). A photograph of finished solar cells is depicted in Figure 4a.

\subsection{Characterization}

The sample was measured by an internally developed sun simulator at ZAE Bayern, the $J-V$ curve was determined under AM1.5 illumination $\left(1000 \mathrm{~W} / \mathrm{m}^{2}\right)$ produced by halogen lamps and solar cell temperature of $25{ }^{\circ} \mathrm{C}$. The height of the lamps were aligned according to the short-circuit current of a calibration sample. The value of parallel resistance $\left(R_{p}\right)$ was determined from the gradient between $-0.9 \mathrm{~V}$ to $-0.7 \mathrm{~V}$ of the dark $J-V$ characteristic and for the series resistance $\left(R_{s}\right)$ from the comparison of the dark $J-V$ characteristic and AM1.5 characteristic of the solar cell at $V_{o c}$.

A reflectance $(R)$ and external quantum efficiency $(E Q E)$ measurement was performed at the physics department of the University of Konstanz using a solar cell analysis system LOANA, fabricated by pv-tools $\mathrm{GmbH}$. The data was corrected for grid shading by using the software Lassie 7.5 of the company pv-tools and the internal quantum efficiency $(I Q E)$ was calculated from the reflectance and the external quantum efficiency:

$$
I Q E=E Q E /(1-R) .
$$

\section{Results and discussion}

The solar cell was measured three times under the sun simulator in order to study the influences of the welded area of the solar cell. The first measurement was performed after the cell processing. Afterwards an additional laser edge isolation line \#2 was applied to exclude the welded area from the active area of the solar cell electrically as depicted in Figure 4a. The efficiency increased by a factor of $55.5 \%$ in between the first measurement (aperture area: $3.24 \mathrm{~cm}^{2}$ ) and the second measurement (aperture area: $2.70 \mathrm{~cm}^{2}$ ). For the last measurement the solar cell was masked with an opening of $1.0 \mathrm{~cm}^{2}$, which corresponded to the optimum size with regard to the front grid. The efficiency increased by a factor of $24.7 \%$ in between second and third measurement.

The champion solar cell produced on keyhole welded silicon foils achieved an efficiency of $11.5 \%$ at an aperture area of $1.00 \mathrm{~cm}^{2}$, more details are stated in Table 1 and depicted in Figure 5. Determined values of the champion cell were $V_{o c}=570 \mathrm{mV}, J_{s c}=29.9 \mathrm{~mA} / \mathrm{cm}^{2}$, $R_{s}=0.61 \mathrm{Ohm} \mathrm{cm}^{2}$ and $R_{p}=8.81 \mathrm{kOhm} \mathrm{cm}^{2}$. The values of the shunt resistance and the series resistance were both reasonable for a one-sun solar cell and did not severely affect the measured cell efficiency. Due to the thin thickness of the silicon foils and the lack of front site texturing 
Table 1. Result of the three measurements of the champion solar cell on keyhole welded silicon foils (cell area $A$, fill factor $F F$, open-circuit voltage $V_{o c}$, short-circuit current density $J_{s c}$ and efficiency $\eta$ ) determined by an internal developed sun simulator under AM1.5 illumination and $25{ }^{\circ} \mathrm{C}$ solar cell temperature.

\begin{tabular}{cccccc}
\hline Measurement & $A\left[\mathrm{~cm}^{2}\right]$ & $F F[\%]$ & $V_{o c}[\mathrm{mV}]$ & $J_{s c}\left[\mathrm{~mA} / \mathrm{cm}^{2}\right]$ & $\eta[\%]$ \\
\hline 1 & 3.24 & 45.4 & 571 & 22.9 & 5.9 \\
2 & 2.70 & 56.0 & 582 & 28.3 & 9.2 \\
3 & 1.00 & 67.6 & 570 & 29.9 & 11.5 \\
\hline
\end{tabular}

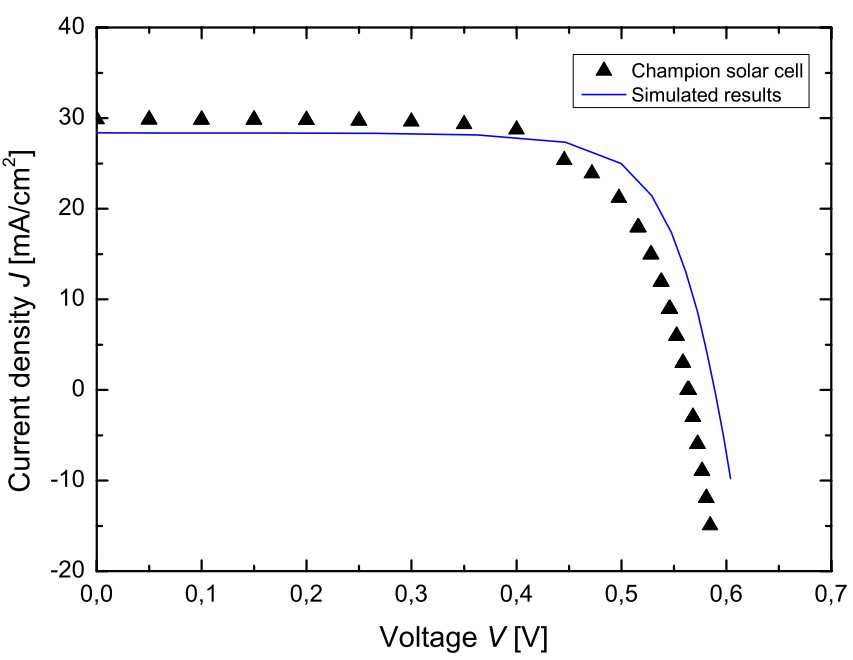

Fig. 5. In-house measured AM1.5 characteristic of the champion solar cell on keyhole welded silicon foils as well as the results of the PC1D simulation.

the short-circuit current density was low. The fact that the efficiency was rising by excluding the welding area was attributed to changes within the silicon because of the welding process. Therefore, solar cells with a high efficiency values can only be build on the unirradiated areas.

Reference solar cells were fabricated in the same way except for the first three manufacturing steps in the process flow (laser cutting, $\mathrm{KOH}$ etching and keyhole welding) on top of $280 \mu \mathrm{m}$ thick float-zone grown silicon wafers. Nine cells with an aperture area of $4.00 \mathrm{~cm}^{2}$ each were fabricated on a single wafer. The mean efficiency value was $10.9 \%$ and the top efficiency value $12.4 \%$.

Reflectance and quantum efficiency measurements revealed high reflectance values below $500 \mathrm{~nm}$ and above $900 \mathrm{~nm}$ as depicted in Figure 6. These values were due to the absence of surface texturing on the front side. Values above $900 \mathrm{~nm}$ were due to the reflectance on the back side of the silicon foils. The $I Q E$ measurement revealed high surface recombination velocity at the front and back side. Results of the back side were better than of the front side due to the BSF.

Using PC1D (Version 5.9) to simulate the champion solar cell and adjusting the model to the measured $I Q E$ characteristics values of the front surface recombination velocity of $1.60 \times 10^{6} \mathrm{~cm} / \mathrm{s}$ and the rear surface recombination velocity of $1.50 \times 10^{4} \mathrm{~cm} / \mathrm{s}$ were determined. More details of the PC1D simulation model are illustrated in Table 2 .

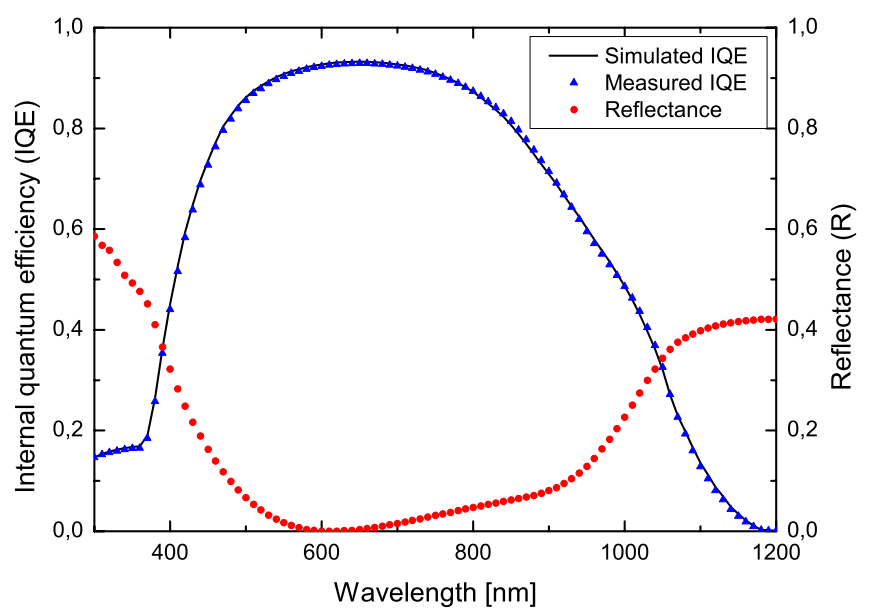

Fig. 6. Characteristics of the internal quantum efficiency (IQE) and reflectance of the champion solar cell on keyhole welded silicon foils as well as the results of the PC1D simulation.

The performance data determined by the PC1D simulation of the champion solar cell $\left(V_{o c}=589 \mathrm{mV}\right.$, $\left.J_{s c}=28.4 \mathrm{~mA} / \mathrm{cm}^{2}, \eta=12.6 \%\right)$ differed in comparison to the measured results. The open-circuit voltage as well as the efficiency was higher than the measured results and the short-circuit current density was lower. This discrepancy was attributed to the fact of unpassivated surfaces in the middle of the solar cell by stacking two silicon foils on top of each other in order to create a band substrate as illustrated in Figure 4b. In our case the active area of the solar cell was affected by stacking at measurement 1 up to $33.3 \%$, measurement 2 up to $20.0 \%$ and measurement 3 up to $5.0 \%$. Despite the surface the two foils were connected with each other at the welding points. This fact is not possible to simulate with an one dimensional software such as PC1D. An additionally issue was that maybe aluminum diffused too far into the silicon bulk material, which was observed sometimes during solar cell manufacturing. However, the measured IQE value were low at high wavelength, this showed that the BSF did not work as designed. This fact was inserted in the simulation model by setting the 1st rear diffusion to a very low value. This value is not realistic for a BSF simulation, but in our case necessary to fit our simulated data on the measured data.

The results of the solar cells are low in comparison to the established standard silicon solar cells, but this was a proof of concept with a simple cell process. Thus, higher efficiencies are possible by applying state of the art techniques like surface passivation and front side texturing. 
Table 2. Selected input and output data of the PC1D simulation plus the comparison between simulated and measured data of the champion solar cell.

\begin{tabular}{ccccc}
\hline & Parameters & Simulated Data & Unit & Measured Data \\
\hline \multirow{6}{*}{ Input } & Device Area & 1.00 & $\mathrm{~cm}^{2}$ & \\
& Emitter contact & 0.61 & Ohm & \\
Thickness & 50.00 & $\mu \mathrm{m}$ & \\
& P-type background doping & $3.25 \times 10^{16}$ & $\mathrm{~cm}^{-3}$ & \\
& Sheet Resistance & 129.50 & $\mathrm{Ohm}_{\text {square }}$ & \\
1st rear diffusion & $4.00 \times 10^{16}$ & $\mathrm{~cm}^{-3}$ & \\
Bulk recombination & 50.00 & $\mu \mathrm{s}$ & \\
& (minority carrier lifetime) & $1.60 \times 10^{6}$ & $\mathrm{~cm} / \mathrm{s}$ & \\
& Front surface recombination & $1.50 \times 10^{4}$ & $\mathrm{~cm} / \mathrm{s}$ & \\
& Rear surface recombination & 589 & $\mathrm{mV}$ & 570 \\
Output & $V_{o c}$ & 28.4 & $\mathrm{~mA} / \mathrm{cm}^{2}$ & 29.9 \\
& $J_{s c}$ & 12.6 & $\%$ & 11.5 \\
\hline
\end{tabular}

\section{Conclusions}

Flexible silicon foils were successfully welded together by keyhole welding. Solar cells at different locations of the welded sample were compared. For high efficiencies it is essential to exclude electrically the area directly hit by the welding laser e.g. by scribing the emitter. The best solar cell on $50 \mu \mathrm{m}$ thin flexible keyhole welded silicon foils reached an efficiency of $11.5 \%$ at an aperture area of $1.00 \mathrm{~cm}^{2}$, with promising values of $F F=67.6 \%$, $V_{o c}=570 \mathrm{mV}$ and $J_{s c}=29.9 \mathrm{~mA} / \mathrm{cm}^{2}$ for a proof of concept. The process flow of the fabrication was simple without clean room environment, no front side texturing and surface passivation. Therefore, higher efficiencies are feasible by applying state of the art techniques. Further investigations with these techniques applied have to show the real potential of this concept.

We thank the Deutsche Forschungsgemeinschaft (No.: KU 2601/1-1 and KU 2601/1-2) for the financial support. Furthermore, the authors are very grateful to Bernhard Fischer from pv-tools $\mathrm{GmbH}$ for the software support.

\section{References}

1. R. Brendel, A novel process for ultrathin monocrystalline silicon solar cells on glass, in 14th European Photovoltaic Solar Energy Conference, 1997, p. 1354

2. J.H. Petermann, D. Zielke, J. Schmidt, F. Haase, E.G. Rojas, R. Brendel, Prog. Photovolt. Res. Appl. 20, 1 (2012)

3. M.A. Green, K. Emery, Y. Hishikawa, W. Warta, E.D. Dunlop, Prog. Photovolt. Res. Appl. 22, 1 (2014)

4. M.M. Moslehi, World-Record 20.6\% Efficiency $156 \times$ 156 mm Full-Square Solar Cells Using Low-Cost Kerfless Ultrathin Epitaxial Silicon and Porous Silsicon Lift-off Technology for Industry-Leading High-Performance Smart PV Modules, in PV Asia Pacific Conference, 2012, p. 11
5. P. Kapur, M.M. Moslehi, A. Deshpande, V. Rana, J. Kramer, S. Seutter, H. Deshazer, S. Coutant, A. Calcaterra, S. Kommera, Y. Su, D. Grupp, S. Tamilmani, D. Dutton, T. Stalcup, T. Du, M. Wingert, A Manufacturable, Non-Plated, Non-Ag Metallization based $20.44 \%$ Efficient, $243 \mathrm{~cm}^{2}$ Area, Back Contacted Solar Cell on $40 \mu \mathrm{m}$ Thick Mono-Crystalline Silicon, in 28th European Photovoltaic Solar Energy Conference, 2013, p. 2228

6. I. Burkert, T. Kunz, Ausgedehnte Siliziumsubstrate, German patent application DE102006037652A1, August 2006

7. T. Kunz, I. Burkert, R. Auer, M. Zimmermann, Towards extended free-standing crystalline silicon thin-films by laser joining, in 22nd European Photovoltaic Solar Energy Conference, 200\%, p. 1946

8. M.T. Hessmann, T. Kunz, I. Burkert, N. Gawehns, L. Schaefer, T. Frick, M. Schmidt, B. Meidel, R. Auer, C.J. Brabec, Thin Solid Films 520, 595 (2011)

9. M.T. Hessmann, T. Kunz, M. Voigt, K. Cvecek, M. Schmidt, A. Bochmann, S. Christiansen, R. Auer, C.J. Brabec, Int. J. Photoenergy 2013, 724502 (2013)

10. K. Cvecek, M. Zimmermann, U. Urmoneit, T. Frick, M. Heßmann, T. Kunz, Thermisches Prozessieren dünner Siliziumsubstrate für die solare Energieerzeugung, in 15th Laser Elektronikprod. Feinwerktech, 2012, p. 91

11. J.H. Werner, R. Dassow, T.J. Rinke, J.R. Köhler, R.B. Bergmann, Thin Solid Films 383, 95 (2001)

12. R. Brendel, Crystalline thin-film silicon solar cells from layer-transfer processes: a review, in 10th Workshop on Crystalline Silicon Solar Cell Materials and Processes, 2000, p. 117

13. M. Mühlbauer, Dünne kristalline Silizium WaferSolarzellen mit Glasträger stabilisiert, Dissertation, FernUniversität Hagen, 2009

14. M. Mühlbauer, V. Gazuz, N. Gawehns, R. Weissmann, M. Scheffler, R. Auer, Novel heterojunction solar cell concept with thin monocrystalline silicon on low cost glass, in 21st European Photovoltaic Solar Energy Conference, 2006, p. 1021 